\title{
Consumption Practices: A Virtue Ethics Approach
}

\author{
Pablo Garcia-Ruiz \\ University of Zaragoza
}

\section{Carlos Rodriguez-Lluesma \\ IESE Business School}

\begin{abstract}
Ethical research on consumption has focused mainly on the obligations, principles and values guiding consumers' actions and reasons for action. In doing so, it has concerned itself mostly with such bounded contexts as voluntary simplifiers, anti-consumption movements or so-called 'ethical consumers,' thereby fostering an artificial opposition between ethical and non-ethical consumption. This paper proposes virtue ethics as a more apt conceptual framework for the ethical analysis of consumption because it takes into account the developmental dynamic triggered by engagement in consumption practices. We build on MacIntyre's goodsvirtues-practices-institutions framework and Beabout's concept of a domain-relative practice and argue that when engaging in consumption activities, agents may pursue goods internal to practices, further their individual life narratives and contribute to the good of their communities, thus developing virtues that perfect themselves both as consumers and as ethical agents.
\end{abstract}

KEY WORDS: consumer ethics, consumer identity projects, domain-relative practice, MacIntyre, virtue ethics

$\mathrm{I}^{\mathrm{N}}$

N THE PAST DECADE, interest in consumption as an area of moral concern has surged (Caruana, 2007; Röcklinsberg \& Sandin, 2013). From the adverse effects of its excesses for individuals, communities and society as a whole (e.g., Barber, 2008; Humphery, 2010; Schor, 1999) to its role in activating corporate social responsibility (Caruana \& Chatzidakis, 2013) or promoting social justice (Micheletti $\&$ Stolle, 2008; Moore, 2004), consumption has increasingly been recognized as a central ethical arena.

The scholarly conversation on the ethical dimension of consumption has been cast mostly in terms of two theoretical paradigms, consequentialism and deontology (Schlegelmilch \& Öberseder, 2010; Vitell \& Muncy, 1992). Consequentialism focuses on the consequences of action, the best alternative being that which brings about the best overall consequences. In contrast, deontology focuses on the rightness of action by comparing the perceived alternatives with a set of established duties that dictate or forbid what is to be done or avoided. In this paper, we argue that while scholars have amply established the need to consider consequences and prin- 
ciples, they must also include virtues if they wish to capture the self-developmental dynamics triggered by consumers as a result of their engagement in consumption practices. The extant literature has been correct in stressing that overconsumption tends to bring about materialism, superficiality, hedonism, and bad taste (Sassatelli, 2007: 117). We concur with this line of research and add that wise and moderate consumption can also be a context and occasion for the development of positive character traits leading to human flourishing.

Our argumentation begins by contextualizing our area of concern through a schematic review of the ethics of consumer behavior, after which we build on Alasdair MacIntyre's (2007) goods-virtues-practices-institutions framework to demonstrate that consumption as a 'domain-relative practice' (Beabout, 2012) constitutes an occasion for the development of virtues and vices.

\section{ETHICS OF CONSUMPTION: MAIN PERSPECTIVES AND THEIR LIMITS}

Research on the ethical aspects of consumption has clustered around two areas: ethical consumerism and consumer ethics. Ethical consumerism, which is an evolution of green consumerism, focuses on the social impact of the current patterns of consumption (Barnett, Cloke, Clarke, \& Malpass, 2005). Topics studied through this lens include fair trade (Moore, 2004), labor standards (Barrientos \& Smith, 2007), shopping malls (Ritzer, 2001), boycotts (Micheletti \& Stolle, 2008), animal welfare (Tseëlon, 2011), voluntary simplicity and downshifting (Etzioni, 1998; Shaw \& Newholm, 2002), among others. From different points of view, this research stream indicates that our current system of consumption has some troubling consequences (Barber, 2008), as an increase in consumption levels seems likely to disrupt the global environmental equilibrium by depleting natural resources (Cohen \& Murphy, 2001), to exacerbate the inequalities in access to goods and services between the privileged and the disadvantaged (Sklair, 2002) and to erode our collective ability to build lasting forms of communal life (Segal, 1999). According to this view, the spirit of consumerism has managed to colonize previously non-market spheres of life such as family, religion, and politics through the labeling of an increasing number of goods and services as commodities and their subsequent exchange on the market (Sassatelli, 2007: 10). Consumer society develops along with the globalization of commodities and cultural exchanges, the increasing role of shopping as entertainment and spectacle, the democratization of fashion, the growth of sophisticated advertising, and the spread of credit to consumers, among other emergent consequences of current overspending (Ritzer, 2001; Schor, 1999).

A second research stream-in which this paper is embedded-namely, consumer ethics (e.g., Albers-Miller, 1999; Fullerton, Kerch, \& Dodge, 1996; Swaidan, 2012; Vitell \& Muncy, 1992), considers consumer behavior and studies "the moral principles and standards that guide the behavior of individuals or groups as they obtain, use and dispose of goods and services" (Muncy \& Vitell, 1992: 298), especially when a decision to consume or decline a certain good or service expresses the agent's concern to abide by a certain moral standard (Cho \& Krasser, 2011). The bulk of this research has focused on questionable behavior (e.g., failing to report undercharges or 
shoplifting) and the dimensions underlying the consumer's judgments (Chatzidakis, Hibbert, Mittusis, \& Smith, 2004; Fukukawa, 2003). In summary, consumer ethics seeks to describe, understand and praise or criticize consumers for their behavior as moral or otherwise (Brinkmann \& Peattie, 2008).

Two competing paradigms, deontology and consequentialism, dominate consumer ethics, with each using a different criterion by which to determine the morality of action (Barnett, Cafaro, \& Newholm, 2005). Deontology focuses on the rightness of action, that is, on whether and to what extent a decision conforms to sound moral principles. According to the Hunt-Vitell model (Vitell \& Hunt, 1990), a deontological evaluation involves comparing the perceived alternatives with a set of established duties (deontological norms). A purely deontological consumer may, for example, see battling child labor as a duty, which would lead her not to purchase clothes from brand $\mathrm{X}$ regardless of other considerations such as lower prices or a convenient location. If deontology focuses on the rightness of action, consequentialism focuses on its outcomes, that is, how much 'good' (or 'utility') the action will produce (Pettit, 1991). A particular behavior (or alternative) is considered the most ethical if rational calculation reveals that it brings a greater balance of 'good' over 'bad' than any other alternative (Vitell \& Hunt, 1990). A purely consequentialist consumer placed in the situation described here would purchase brand $\mathrm{X}$ clothes if she believed that purchasing them would bring more good than bad, regardless of the nature of the actions involved.

Empirical research has shown that individuals typically use both principles and consequences as evaluation criteria (Mayo \& Marks, 1990; Vitell, 2003; Vitell \& Hunt, 1990; Vitell, Singhapakdi, \& Thomas, 2001). However, evidence also suggests the relevance of other important aspects of consumer behavior that deontology and consequentialism tend to ignore (Kozinets \& Handelman, 1998; Shaw, Shiu, \& Clarke, 2000). Most relevant among these is the role of identity (e.g., Belk, 1988; Friedman, 1994), a significant predictor of a person's concern with ethical issues in consumption (Cho \& Krasser, 2011).

Early work by Belk (1988) established that consumers use key possessions to extend, expand, and strengthen their sense of self. Since the emergence of that work, a strong research focus has been placed on the ways in which people use consumption to maintain their sense of identity over time (Ahuvia, 2005). This line of research has revealed that consumers engage in identity projects (Arnould, 2006) by actively re-elaborating the symbolic meanings offered in the market to reaffirm their personal and social characteristics as well as to promote their identity and lifestyle goals (Arnould \& Thompson, 2005: 871). This is true not only for members of specific groups such as voluntary simplifiers, eco-Christians, kibbutz dwellers, the Pennsylvania Dutch Amish, downshifters, slow food movement followers, green activists and the like (Lorenzen, 2012) but also for non-affiliated individuals who, despite a pervasive consumer culture, use consumer goods to express their feelings and beliefs, build relationships, and create a sense of identity for themselves (Shaw $\&$ Newholm, 2002) in such a way that everyday consumption becomes an important occasion for moral development (Luedicke, Thompson, \& Giesler, 2010). 
Further research has shown that these everyday behaviors are frequently fueled by a quest for a coherent identity narrative (Marion \& Nairn, 2011; Murray, 2002; Thompson, 1996; Thompson \& Haytko, 1997). In addition to perceiving their identities as a list of attributes, consumers link these attributes to key episodes in their lives, which in turn are strung together to form a story they tell themselves and share within their communities. This storyline allows people to make sense of who they are and provides a connected identity from past to present and into possible imagined futures (Ahuvia, 2005: 172). To illustrate, a 'green' lifestyle implies the placement of consumption activities within their relevant context. For many people, green practices are not isolated decisions or actions but components of an ongoing project of sustainable consumption that aims at different goals, such as being healthier, living more spiritually, attaining self-sufficiency, saving money, or realizing social justice concerns, among others (Lorenzen, 2012: 95).

As indicated above, deontology and consequentialism, while offering a basis for the moral evaluation of decisions and providing actors with pathways for moral reasoning (Anscombe, 1958), are ill-equipped to address this 'identity turn' evident in consumption practice and theory. Their emphasis on conscious decision-making has favored ethical dilemmas as a preferred object of attention, resulting in a neglect of the crucial role of the agent's character in moral reasoning (Melé, 2009) as well as of the practical, narrative and collective contexts in which that agent is embedded. These latter factors are central to a virtue ethics perspective.

Different versions of virtue ethics exist (Swanton, 2003). Similarly to MacIntyre (1992; see also Aranzadi, 2011), we consider virtue ethics to be concerned not only with virtues but also with principles (as deontology does) and with goods (as consequentialism does). Unlike deontology, however, virtue ethics contemplates such factors as the agent's motives, intentions, habits, character and relations, and unlike consequentialism, virtue ethics maintains that some principles should never be broken (see Ferrero \& Sison, forthcoming). Most importantly, virtue ethics consequently establishes the connection between what the agent does and who the agent becomes, holding that the consequences that an action leaves for the agent are more important than any possible external result of that action (Sison \& Fontrodona, 2012). With its emphasis on character development, virtue ethics provides a developmental dynamic absent in both consequentialism and deontology. Boycotting, for example, emotionally expresses the individuality of the consumer and serves as a vehicle for moral self-realization, connecting "individuals to their deeper moral self" (Kozinets \& Handelman, 1998: 479). What people consider in consumption decisions such as boycotting includes not only the duties and consequences of their actions but also the coherence between their choices and the kind of person they are or want to be.

In summary, we contend that virtue ethics can account for consumers' ethical concerns by considering not only the questions "what is the right thing to do?" (deontology) and "how can I act so as to produce the most good for the most people?" (consequentialism) but also "how can I lead a good life" and, most importantly, "what kind of person do I want to be?," which actually constitutes the central question of virtue ethics (Barnett, Cafaro, \& Newholm 2005: 17). This shift is consequential for our consideration of consumer ethics because it directs our attention from more 
or less specific dilemmas to a consideration of the kind of person one should be in order to act morally. We now turn to a brief presentation of MacIntyre's (1994, 1999, 2007; MacIntyre \& Dunne, 2002) version of virtue ethics summarized in the goods-virtues-practices-institutions framework. Based on MacIntyre's ideas, we will argue that consumption is a domain-relative practice (Beabout, 2012) that enables consumers to develop virtues with which to achieve the goods internal to the practices to which consumption refers, the goods of consumers' individual lives, and those of their communities.

\section{A MACINTYREAN VIRTUE ETHICS APPROACH TO CONSUMPTION}

\section{The 'Goods-Virtues-Practices-Institutions' Framework}

While several different versions of virtue ethics are available (Swanton, 2003), we build on Alasdair MacIntyre's $(2007,1999)$ framework because it provides an articulate and distinctive proposal to consider consumption activities whose ethical dimension we wish to analyze.

To the question, "What is the good life and how can I go about living it?," MacIntyre (2007: 293) responds that the good life consists of "the life spent in seeking for the good life for man [sic]," that is, in the quest to ascertain what 'good' means for oneself in particular. To understand what this sentence means and its importance for an ethical examination of consumption, we now turn to a schematic explanation of the central concepts of good, virtue, practice and institution, with a particular emphasis on the role of virtue in the pursuit of good at the practice, individual narrative and community levels. Much of this explanation will already be familiar (for general overviews of MacIntyre's application to business, see Beadle \& Moore, 2006,2011 ), but it is necessary to outline the basis before drawing its implications for a virtue-based consideration of consumption.

Goods

Goods provide us with reasons for acting, in other words, that "for the sake of which" we act (MacIntyre, 1999: 64ff.). MacIntyre establishes a distinction between different types of goods by means of the hypothetical example of a child who learns to play chess (2007: 188). Initially uninterested in the game, he agrees to play in exchange for candy. Eventually, however, he learns to enjoy the game itself. MacIntyre uses this story to illustrate the difference between external and internal goods. External goods such as prestige, status and money — or candy, in the chess example — do not arise intrinsically from practice and are scarce and subject to competition. These goods are not characteristic of any particular practice and can be attained through many practices. Cooking, fashion design, law and a myriad of other practices can grant prestige and wealth. External goods are objects of competition such that the emergence of a hierarchy among practitioners in terms of external goods is inevitable (MacIntyre, 2007: 178).

In contrast, internal goods are those accessible only from within a practice, such as the specific achievements, skills, and satisfaction of participating in the practice (Sayer, 2003: 347). In the case of the chess example, such goods would include a 
"certain highly particular kind of analytical skill, strategic imagination and competitive intensity" (MacIntyre, 2007: 188). Essentially tied to internal goods are the standards of excellence of the practice to which those goods are internal. All practices establish standards of excellence and are partly defined by those standards (MacIntyre, 2007: 175). In chess, for example, we find good and bad players, a distinction that does not rest on personal preference but on the degree to which they achieve (or in extraordinary cases, enhance) the standards of excellence of the game. In other words, goods internal to the practice may only be qualitatively evaluated against shared standards.

Internal goods and standards of excellence may change endogenously through the process of emulation (Keat, 2000; MacIntyre, 2007: 178ff.). The best way to understand emulation is to see it as being based on "the more fundamental desire to 'excel': in this context, to perform the activities of a practice to the highest level, as judged by its standards" (Keat, 2000: 118). Internal goods are indeed the outcome of a competition to excel, but it is characteristic of them that their achievement is a good for the whole community participating in the practice, as the best practitioners enrich the standards of excellence for all (MacIntyre, 2007: 178). When a creative chef, for example, invents a new dish or combination of flavors or ingredients, he or she raises the standards of excellence for all other chefs, who now have a new reference point from which they can extend their capabilities as chefs.

\section{Virtues}

Virtues are those praiseworthy character traits that lead to human flourishing (Audi, 2012; Hursthouse, 1999) through the provision of good reasons to act and the willingness to follow up on decisions made inasmuch as they "enable the achievement of three distinct kinds of goods: those internal to practices, those which are the goods of an individual life and those which are the goods of a community" (MacIntyre, 1994: 284). They include courage, justice, tolerance, patience, compassion, persistence, intelligence, imagination, and creativity, among many others. Virtues are related to, but distinct from, values. A virtue is something we have (or not), while valuing is something we do. The mere valuing of austerity does not make us austere. We must practice austerity if we want to become austere people. Virtues enable us to achieve our aspirations and values (Moore, 2005b: 244).

Virtues help us understand "what more and what else the good life for man (sic) is" (MacIntyre, 2007: 207). To achieve even moderate success in their moral development, agents need such virtues as discernment, judgment and prudence. These types of virtues, for example, are sought in so-called "simplicity circles," the small groups within which simplifiers engage in moral identity work, that is, in efforts to discern what is good for them and how they can realize it to be "good people" (Grigsby, 2004: 54). Because the means of "living simply" are not explicit, voluntary simplifiers interact across space, culture and class to clarify how to enact beliefs, values, and concerns about simplicity (Cherrier \& Murray, 2007: 3).

Virtues help us pursue goods in three domains-practices, individual life narratives, and communities - as well as avoid the corruption of practices by the institutions in which they are housed. 
Practices, Life Narratives, and Communities

MacIntyre defines practice in a very precise way:

Any coherent and complex form of socially established cooperative human activity through which goods internal to that form of activity are realized in the course of trying to achieve those standards of excellence which are appropriate to, and partially definitive of, that form of activity, with the result that human powers to achieve excellence, and human conceptions of the ends and goods involved, are systematically extended. (MacIntyre, 2007: 175)

The range of practices is wide: arts, sciences, games, and the making and sustaining of family life, among many others, all fall under this concept (MacIntyre, 2007: 176). Practices constitute the primary site in which not only the "human powers to achieve excellence" but also understanding and appreciation of "ends and goods" are extended. For example, there is such a thing as extending one's capacity to be an excellent chess player, as well as having a better grasp of what chess is about. More generally, the virtues of justice, courage and honesty can be extended to accepting criticism and submitting oneself to the standards of excellence in any practice (MacIntyre, 2007: 191). In After Virtue, MacIntyre provides an initial definition of virtue in the context of practices as "an acquired human ability the possession and exercise of which tends to enable us to achieve those goods which are internal to practices" (MacIntyre, 2007: 178).

Virtues not only help in the pursuit of goods internal to practices but also aid in protecting practices from corruption, which may always be occasioned by the exclusive or dominant pursuit of external goods by institutional agents (MacIntyre, 2007: 194). Internal and external goods are frequently found at odds because practices are embedded in the institutions they need in order to survive: researchers need research centers, musicians need music companies, and comedians need theatres and television networks. Institutions are structured in terms of power and status, and they distribute such external goods as money, power and status as rewards. They cannot do otherwise if they are to sustain not only themselves but also the practices of which they are the bearers (MacIntyre, 2007: 180). However, when practitioners pursue only external goods and engage in competition with others that leads to the neglect of internal goods, they in fact make the practice hollow. The consequences are close to the "overjustification effect," which describes the undermining effect that an extrinsic incentive has on the intrinsic motivation to perform a task (Lepper, Greene, \& Nisbett, 1973): practitioners lose interest in the internal goods of the practice and remain engaged in it mostly for extrinsic reasons. As a consequence, "the ideals and the creativity of the practice are always vulnerable to the acquisitiveness of the institution, in which the cooperative care for common goods of the practice is always vulnerable to the competitiveness of the institution. In this context the essential feature of the virtues is clear. Without them, without justice, courage and truthfulness, practices could not resist the corrupting power of institutions" (MacIntyre, 2007: 182). Absent these virtues, worthy and economically viable scientific (von Krogh, Haefliger, Spaeth, \& Wallin, 2012) or artistic (Beadle, 2013) projects might be neglected in favor of less worthy but more profitable initiatives. 
The second domain in which virtue is exercised is the unity of one's life as a whole. Individuals normally participate in several practices, with each one providing its own internal goods, which may conflict with those of other practices. The internal goods afforded by working seventy hours per week as a consultant may conflict with those afforded by the practice of parenting. Practices themselves do not provide us with a method to rank those conflicting goods, and yet, "for each individual there is the question whether it is good for him or her that the goods of this or that particular practice should have this or that place in her or his life" (MacIntyre, 1999: 66). MacIntyre's response to this necessity to order particular goods is intimately tied to his conceptions of life as a quest. Human life assumes the form of a quest for the good (MacIntyre, 2007: 219). This notion of the good that we pursue is our telos (goal), the ultimate "for the sake of" that unifies and bestows meaning upon each particular "for the sake of" provided by any practice. This quest for an ultimate goal —indeterminate as it may be at the beginning — provides a progressive revelation of that goal:

It is in the course of the quest and only through encountering and coping with the various particular harms, dangers, temptations and distractions which provide any quest with its episodes and incidents that the goal of the quest is finally to be understood. A quest is always an education both as to the character of that which is sought and in self-knowledge. (MacIntyre, 2007: 219; see also Moore, 2005b: 246)

Understanding life as a quest provides a new context for virtues. Beyond their capacity to sustain practices and pursue the goods internal to them, virtues "sustain us in the relevant kind of quest for the good, by enabling us to overcome the harms, dangers, temptations and distractions which we encounter, and which will furnish us with increasing self-knowledge and increasing knowledge of the good" (MacIntyre, 2007: 219).

Finally, virtues relate to the community and tradition in which the actor is embedded. Actors do not start their lives devoid of social ascriptions but find themselves in roles whose content evolved before they occupied them and will continue to do so both during and after their lives (MacIntyre, 2007: 200). Those roles refer to the communities in which they are played and also to the traditions of which they are a part because they are only understandable in terms of the shared history and values that characterize the community. A tradition is not a mere container or sequence of practices but "an historically extended, socially embodied argument, and an argument precisely in part about the goods which constitute that tradition" (MacIntyre, 2007: 222). Humans become capable of moral reasoning because they are embedded in a common moral frame that precedes them and from which they draw shared moral criteria. In other words, in allowing the agent to draw on objective moral criteria, this precedent moral framework makes a general evaluation of 'good' and 'bad' that are possible both within practices and for agents in the construction of their personal narratives. Conversely, when engaging in arguments about the tradition's fundamental agreements with others external or internal to that tradition, individuals enrich that tradition and further its progress (MacIntyre, 2007). 
In summary, virtues sustain individuals as participants in practices, as agents in their individual narratives in their quest for a unified life, and as members of a community.

\section{Consumption as a Domain-Relative Practice}

While consumption cannot be considered a full-fledged practice according to MacIntyre's precise definition, it may be conceived as a "domain-relative practice" (Beabout, 2012). The notion of a "domain-relative practice" is implicit in the work of MacIntyre (MacIntyre \& Dunne, 2002) and refers to activities that, when interlocking with other practices, "1) possess internal standards of excellence identifiable to practitioners, and 2) are always related to another particular domain" (Beabout, 2012: 414): one teaches a subject, writes or speaks on a topic, or coaches a sport, but there is no detached, pure, abstract form of teaching, coaching or speaking. Teaching is never more than a means because it has no point or purpose above and beyond the point and purpose of the activities to which it introduces students. Even so, teaching contains its own internal standards of excellence that require specific character traits that enable the pursuit of that excellence (MacIntyre \& Dunne, 2002: 7-9). Analogously, consumption may be considered a domain-relative practice inasmuch as it is related to other practices to which it is subservient and possesses its own standards of excellence.

Consumption and Its Relation to Other Domains

All practices entail consumption (Warde, 2005), and in many of them, consumption goods play a key role, as acquiring them grants access to the practice's internal goods (Keat, 2008; Sayer, 2003): for example, bird watching requires the aid of powerful binoculars, playing music necessitates a good instrument, and scholarship implies access to rigorous books and papers. Certainly, being a competent consumer differs from being a practitioner, but there are features of the relationships inherent within practice that competent consumers will also need to acknowledge to judge the products of practice and proper relationships between practitioners. Good consumers, for example, will need to acknowledge authoritative judgments, and their appreciation of the quality of products, though different from that of those who produce them, likewise entails a period of apprenticeship. ${ }^{1}$ Wine consumption as a domain-relative practice, for example, is subordinated to the practice of winemaking, and the internal goods of the latter provide the relevant standards of excellence for the former.

Furthermore, consumption activities relate to full-fledged practices through 'consumption projects,' understood as individuals' capacity to appropriate and use the meaningful properties of objects in their quest for the good life through engagement in those full-fledged practices (Belk \& Pollay, 1985; Kopytoff, 1986). Marion and Nairn (2011) illustrate this relationship in their exploration of the ways in which teenage French girls use fashion items and discourse to construct their evolving identity from their recent childhood to their futures as flourishing, fully grown women. The personal identity of a teenage girl, through her appearance management, appears as a threefold process: demarcation (I am what you are not), meaning attribution (to produce and recognize a look among other looks), and life projection (the kind 
of woman I want to be) (Marion \& Nairn, 2011: 53). For teenagers, the production and recognition of a look are activities that rest on skills that result from their socialization as consumers within personally experienced milieus: first, the skill of "knowing how to see and be seen" as a precondition for imitation, assimilation, differentiation, distinction, and variety seeking, among other activities, and second, the skill of "knowing how to choose." In both cases, the skill is a matter of practical knowledge that is constituted around a string of approvals and disapprovals from family, friends, classmates and associates. Embedded in their social network and using materials from their cultural milieu, these girls practice the art of 'bricolage' to create their own narrative identities (Marion \& Nairn, 2011: 29, 51).

Consumption and Standards of Excellence

Every practice involves a set of standards of excellence that help practitioners identify what counts as good or bad, genuine or spurious, and exemplary or worthless (Keat, 2000: 27). Domain-relative practices are also guided by standards of excellence, which depend on the internal goods of the main practice with which those practices interlock.

User communities around a brand or specific product provide a crisp illustration of how consumption may be guided by standards of excellence. Brand communities can be defined as "specialized, non-geographically bound communities based on a structured set of social relationships among admirers of a brand" (Muniz \& O'Guinn, 2001: 412). They include Harley-Davidson (Fournier, 2000), Jeep (McAlexander, Schouten, \& Koenig, 2002), and Saab owners (Muniz \& O'Guinn, 2001), followers of pop celebrities on social media networks, customers of natural cosmetic products, and/or Lego toy experts (Kornberger, 2010: 147-53), among many others. Some of those community members stand out because of their skills or because of their knowledge about the goods and values associated with the brand. There are, for example, expert Saab drivers who know how to realize the car's legendary values of safety and durability. There are also makeup artists who excel at making the most out of the health benefits of natural cosmetics. Some Lego users not only are experts at the game, but also expand its educational and entertaining possibilities through creative recombination. The rest of the members in the community recognize those practitioners as role models because they make a good, genuine, and exemplary use of the brand's values (McAlexander et al., 2002), which allows them to be excellent practitioners. Hence, one of the defining characteristics of these communities is the distinction between 'legitimate' and 'illegitimate' consumers, that is, between those real connoisseurs of the brand's values and those who frequent it just because it is fashionable to do so or for any other reason that 'real' fans may deem spurious (Muniz \& O'Guinn, 2001). Illegitimate users constitute a threat to the community because they may corrupt the brand's meaning by privileging goods extrinsic to it. True members seek the subsistence of the values that define the community offering them a shared identity. In making an effort to become authentic users, consumers may perfect themselves as practitioners (i.e., drivers, makeup artists or players) along the lines of the standards of excellence provided by the appropriate use of the brand. 
Standards of excellence and the pursuit of goods internal to the practice of reference are also clear in more conventional and dispersed consumption practices. If we take homemaking as the practice of reference, it is clear that such consumption activities as provisioning and furnishing a home contain standards of excellence that are incarnated in shared references such as those celebrities who stand as paradigms of cuisine (e.g., Ferran Adrià) or home décor (e.g., Martha Stewart), for example. The specialized press (including blogs, specialty TV channels and other media) proposes them as gurus so that a homemaker may identify the shared standards in their field of interest. In general, the same personal satisfaction, pride and sense of dignity (Douglas \& Isherwood, 1979: 45) can be noticed in a person who has changed all of the pieces of furniture in her living room, in a person who has skillfully cooked a barbeque or in a parent who has successfully put a baby to sleep using a rattle. Judging whether the selection, purchase and use of furniture, vegetables or a rattle denote skill or a lack thereof implies subjecting those acts of consumption to the internal goods of homemaking (most likely relating to mutual care and the raising of children or, more generally, to turning a house into a home).

In the following section, we argue that consumption acts serve as an occasion for virtue development and elaborate their role in the contexts of practice, individual life narratives and community/moral traditions.

\section{CONSUMPTION AND VIRTUE DEVELOPMENT}

\section{Virtues in Consumption: Practices}

To pursue the goods internal to reference practices through consumption, consumers need virtues. Constancy and humility are clear examples in that they are needed for any practice. The former is needed in every practice (MacIntyre, 2007: 242) because the achievement of the goods internal to every practice requires of the agent an ongoing commitment to the pursuit of the goods of practices in such a way that they are sustained (Beadle, 2013: 681). Humility, in turn, is necessary because practitioners will have to submit to the standards of excellence and the best achievements available at the moment, which implies admitting one's own subordination to experts within the practice (Keat, 2000: 27). The learning process requires acknowledging what is owed to whom, being willing to face any risk that may arise in the learning process, and heeding any hint as to one's own limitations and ineptitudes. To use MacIntyre's own words, "If, on starting to listen to music I do not accept my own incapacity to judge correctly, I will never learn to hear, let alone to appreciate, Bartok's last quartets" (MacIntyre 2007: 177).

Some other virtues, however, seem particularly unique to consumption as a domain-relative practice. Several authors have proposed terms referring to the virtuous use of goods and services while engaging in practices. Gambrel and Cafaro (2010: 90), for example, propose 'simplicity' as a specific virtue of consumption and characterize it as "a conscientious and restrained attitude toward material goods" that promotes human and social flourishing in liberating agents from excessive preoccupation with the material. Roberts (1998: 15) defines frugality as "caring or sparingness in the use or supply of food and other resources." Other virtues in this 
field include temperance and austerity. We refer to the central virtue of consumption as 'moderation' and characterize it as the proportionate use of resources that befits the standards imposed by the practice to which the consumption act refers and furthers the goods of the reference practice, that of the consumer's personal life narrative, and those of his/her community and moral tradition. Of course, moderation is closely related to the virtues mentioned above. Our conception of moderation agrees, for example, with Gambrel and Cafaro's definition of 'simplicity' in that both simplicity and moderation require more conscious and deliberate consumption decisions. We differ in our conception, however, in that 'simplicity' tends to imply a decreased consumption, while we see moderation as depending on the interplay between the consumer's character and the context in which she is embedded. As with any Aristotelian virtue, the golden mean will not be the same for every consumer. Following Aristotle's lead (Nicomachean Ethics, 1106a26-b28), we can represent moderation as a golden mean between two vicious extremes - in this case, between overconsumption and underconsumption, as shown in Figure 1.

Overconsumption includes such vicious behaviors as gluttony, obsession with material goods, prodigality, wastefulness and lavishness. Underconsumption refers to behaviors that hamper human flourishing such as avarice, meanness, stinginess or the abstinence of food leading to health hazards. Between them lies moderation as a 'golden mean,' that is, as a middle point that represents excellence in consumption. To achieve excellence moderation needs the help of practical wisdom because the mean between the two extremes is not the same for every consumer. Virtue is relative to the particulars of the case (Nicomachean Ethics, 1106a36-b7). A proportionatethat is, virtuous - amount of food for an athlete would mean gluttony for others. The same can be applied to the young artist who spends her savings on premium oils and canvasses or to the music student who purchases a yearly pass to a concert hall, even if those expenses mean going without what others may consider "more basic needs."

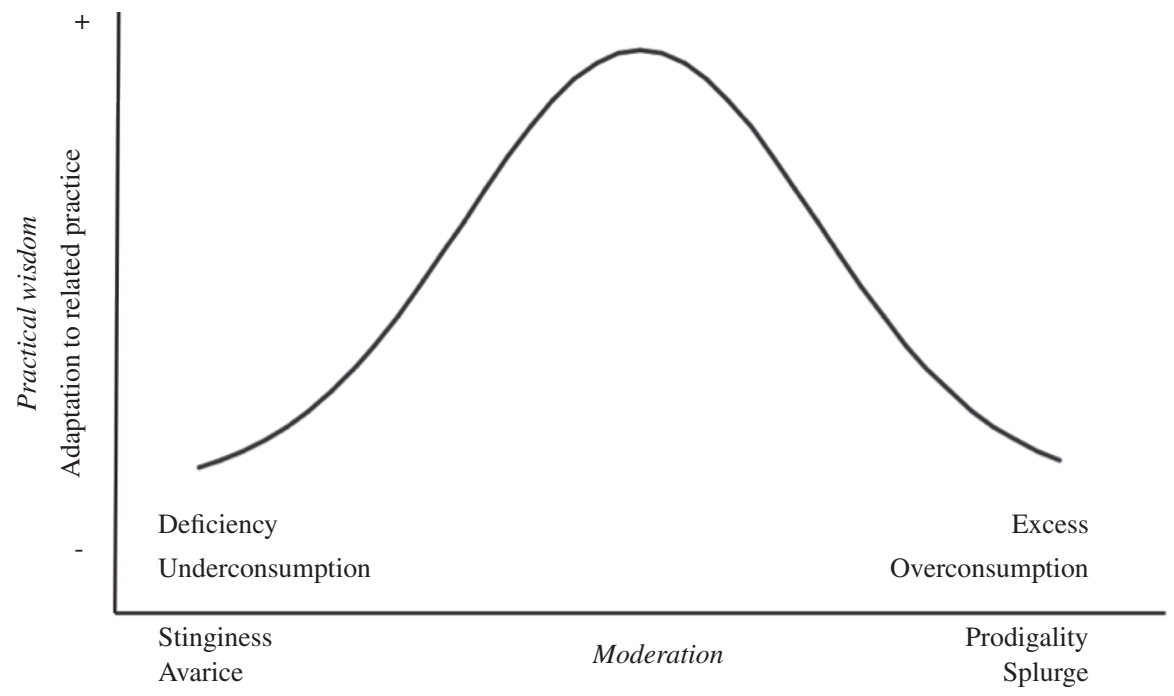

Figure 1: Virtuous consumption as a domain-related practice: moderation and practical wisdom (source: author's elaboration, based on Bright, Winn, \& Kanov 2014) 
Practical wisdom is the habit of mind through which one is excellent in each case at judging the available means to accomplish a worthy end. As with any virtue, practical wisdom can be enhanced, as judging "is not merely an intellectual exercise of subsuming a particular under rules or hyper-norms. Judgment is an activity of perceiving while simultaneously perfecting the capacity to judge actions and choices and to perceive being" (Koehn, 2000: 17). Figure 1 above shows how consumers need practical wisdom to reach the golden mean of moderation, that is, the adequacy between their consumption practices (as relative to some full-fledged practice) on the one hand and the achievement of those goods internal to the practice on the other hand. By way of illustration, the practice of cycling calls for adequate equipment as well as the ability to discern, among other things, how to use it or when it is in need of repair or replacement. However, if one spends too little and purchases defective equipment, it will be difficult for him to engage productively in the practice. However, there is also such a thing as spending too much. One may purchase a bike that greatly exceeds one's athletic capacities and commitment to the practice of biking. This consumption decision may be a sign of ignorance, a lack of experience or one's desire to show off and/or seek admiration or other goods external to the practice of cycling. For this reason, overspending usually attracts scorn on the part of experienced practitioners.

In sum, such virtues as moderation, practical wisdom and constancy help consumers preserve the internal goods of the practices in which they engage by fending off deficient or excessive concern with the resources consumed. In the next section, we argue why moderate consumption is also an occasion for the discernment and realization of the consumer's personal good through the crafting of his or her life narrative.

\section{Virtues in Consumption: Individual Life Narratives}

Virtues are needed to achieve not only goods internal to the practice of reference but also the good of one's life as a whole. As argued above, agents need to integrate the set of potentially conflicting goods they may pursue within the different practices in which they engage in a personally meaningful way. In this respect, selecting consumption goods can become the occasion to order and prioritize moral goods into a coherent individual narrative. Virtues help consumers make a fair selection. Provisioning, as characterized in Miller's (1998, 2001) ethnographic studies, offers a vivid case for consumption as a practice relative to the practice of sustaining family life. For most households, the act of buying goods (provisioning), far from counting as individualistic behavior, is mainly directed at other people, particularly loved ones (Miller, 1998: 40). Selecting goods expresses a relationship between the shopper and a particular other individual, such as a child or partner about whom the shopping agent cares. In most cases, the shopper's desires become subordinate to those of others, so that "love is not only normative but easily dominant as the context and motivation for the bulk of actual shopping practice" (Miller, 1998: 22). Miller observed and interviewed old and young couples (both childless couples and those with children), single mothers, friends, senior citizens, and men and women 
who shop by themselves and with others. In almost all of those situations, the idea of shopping for others was ubiquitous, the purpose being not only to please another person but also to show them that one cares in practice. For a homemaker, this implies buying a "particular brand or flavour, in relation to her sense of not only what the other individual wants, but her reasoning as to what would improve that individual (in practice, the two may be compromised in the form of what she can get the wretched object of love to actually eat!)" (Miller, 1998: 108). On some occasions, reaching an agreement proves difficult, as the criteria that bestow meaning on our decisions may be incompatible. One of the informants in Miller's (2001: 121ff.) studies, for example, expressed difficulty with regard to her ordinary shopping. Peggy is a vegetarian who cares about food. Her husband, Joseph, is Jewish. Both have agreed to follow a series of dietary restrictions dictated by Judaism. Peggy feels like a mediator between the supermarket and their dining table, which is why she gives him a warning when she finds something that her husband should not eat. Peggy, like countless other shoppers, devotes effort and attention to the ordinary provisioning of food so that another finds it not only appropriate but also tasty. From her point of view, this task takes on a considerable moral and educational value that is due more recognition than it normally receives (Miller, 1998: 21). Selfishness, impulsiveness, mindlessness or the desire to belong in a group can and often are reasons for shopping, and one can often make a poor choice in shopping for others even though the action be motivated by affection for them. However, Miller's abundant findings suggest that consumers (shoppers, in this case) effectively, even if not always consciously, use shopping as a vehicle to realize the goods internal to making and sustaining family life.

In the context of anti-consumption practices (themselves a form of consumption), Black and Cherrier (2010) explored the relationship between identity and sustainable practices and found a clear link between the informants' hierarchy of goods and the sustainable practices in which they are engaged. Specifically, their study examined various daily anti-consumption practices, the meanings that consumers gave to those practices and how those practices were incorporated within wider discourses of sustainable living, which expressed the type of life that informants considered good for themselves and for their communities. Sustainability can be considered a virtue of those consumers who seek to lead a good life by engaging in "sustainable" practices. Sustainable consumption refers to "the use of goods and related products which respond to basic needs and bring a better quality of life without jeopardising the needs of future generations" (Black \& Cherrier, 2010: 438). It includes such practices as minimizing the use of natural resources and toxic materials as well as the emissions of waste and pollutants over the life cycle. The informants in Black and Cherrier's (2010) study reported examples of what eco-friendly products they incorporated (or not) in their daily lives, and what criteria they used to make those decisions. These criteria originated mainly from conflicting identities. Within their daily lives, they embraced diverse identities, such as, for example, being a mother, wife, sister, artist, teacher, and lawyer. The management of the boundaries between any pair of these identities explained their inclination toward some practices over others. Kate, one of the informants, for example, considered the idea of purchasing 
organic milk attractive, but her uncertainty about its quality and her feeling that it was too expensive conflicted with the identity of a mindful homemaker that she strived to be. Francis, another informant, is a mother. She eats organic food, grows vegetables, and uses public transport, but she refuses to purchase and use environmentally friendly cleaners. Her refusal is linked to her identity as a mother. Francis refrains from buying these cleaners because she thinks they do not clean well, and using them would challenge her conceptualization of 'being a good mother' as a homemaker, for which cleanliness is critically important (Black \& Cherrier, 2010: 443). As these examples show, individuals' actual and desired identities imply strong and nested commitments toward concrete goals. The adoption of a specific set of practices allows agents to pursue the kind of person they want to be. In engaging in such practices, they develop virtues that help them discern and realize what is good for themselves and for their significant others.

\section{Virtues in Consumption: Community and Tradition}

Virtues are needed to pursue the goods of one's community, which, in turn, as a collective bearer of a specific moral tradition, shapes the understandings that individuals have of themselves and of the practices in which they engage. Moderate and wise consumption decisions, in contributing to the achievement of the internal goods of practices, also contribute to the good of the community and moral tradition in which those practices are embedded. Virtuous consumption preserves not only the material resources of the community but also its moral fabric by keeping the external goods of practices at a reasonable level. Such decisions as which expenses are reasonable, which objects should be used for which purposes, or which spending limits are not to be surpassed help sustain practices focused on internal goods and to keep conversations focused on which goods are worth pursuing.

The voluntary simplicity movement (for general views, see Elgin, 2010; Etzioni, 1998) provides a clear illustration of the role of moderate and wise consumption in a community tradition. The philosophy of voluntary simplicity calls into question the meaning of 'the morally good life' in modern society and posits a less materialistic lifestyle as a more personally fulfilling, spiritually enlightening, socially beneficial and environmentally sustainable lifestyle (Johnson, 2004: 527). Voluntary simplifiers resist consumption-intensive lifestyles so that their lives become "clearer, more direct, less pretentious, and less complicated" (Elgin, 2010: 153) by refusing to purchase items that fail to improve their level of happiness (Alexander \& Ussher, 2012) and rejecting consumption activities that do not correspond to their self-concept (Craig-Lees \& Hill, 2002).

Simplicity promotes the good of the whole community because it opposes materialism, which leads consumers to prioritize the appreciation of things over people. On the contrary, simplicity may give rise to a more developed sense of citizenship and communal responsibility, helping consumers be content with their moderate spending levels and thereby releasing social tension (Schor, 1992). Furthermore, healthy societies depend on an equally healthy ecosystem, which is presently threatened by immoderate consumption levels. Voluntary simplifiers certainly contribute to a 
better society through the direct effects of their practices of decreased consumption, but they may perhaps make a greater contribution by showing their fellow citizens that consuming less need not be a disgrace but may actually improve their lives.

Homemaking provides a fitting second example of the relation of consumption to the good of a community and the role of a moral tradition through reference to a full-fledged practice. Homemaking is a setting in which non-affiliated consumers frequently engage in arguments about what constitutes the goods of their particular community - a family, in this case - what to do in case of a conflict among several goods and, in general, who should do what, when and for which reasons. Given that - as we argued above — virtue is relative to the particulars of the case, equally virtuous arrangements may vary from home to home according to income, schedules or life projects. Hochschild (2012) offers a clear illustration of these arguments. Exploring the division of labor within the home, the Author shows how two-earner families with young children follow different strategies in their difficult attempt to reconcile the demands stemming from work and family. Some families try to reduce the time they spend on work. Some others try to justify a decrease in the amount of labor required of even diligent homemakers. They may, for example, question the necessity of cleaning, doing the dishes or washing the kids every day. One of the informants in the study wondered, "Why can't kids wear the same pants three or four days in a row?" (Hochschild 2012: 195-96). Many women try to get their partners to participate in house chores. Some certainly achieve this goal, but some men resist such demands. Most men in her sample used a strategy of needs reduction. A rather extreme case was that of a salesman and father of two who explained that he never went shopping because he did not need anything. He did not need to take clothes to the laundry to be ironed because he did not mind wearing a wrinkled shirt. Nor did he, according to his report, need much furniture in the house or any food other than cereals for dinner. His wife, however, had a different understanding of what an appropriate level of spending in a home was. For her wearing a wrinkled shirt, not having appropriate furniture in the house or going on a cereal diet because one does not want to cook, made no sense (Hochschild 2012: 198). Making decisions on which expenses are reasonable and which goods are worth pursuing people engage in arguments about the tradition on what good homemaking is. In so doing they may enrich that tradition and further its progress.

In summary, when deciding what to choose, what to buy, what to use or discard, and what to recycle or repair, consumers use standards rooted in the practices around which they craft their individual life narratives. Those standards receive their meaning and importance in part from the internal dynamics of the practices themselves as well as from the moral tradition embedded in the community in which consumers develop their life projects. Through their consumption decisions, individuals pursue three distinct types of goods: a) those goods internal to the practices in which they engage to further their life projects (e.g., to be a good homemaker); b) those goods of their lives as a whole, which they unify through their life narratives (to lead a good life); and c) the goods of the communities of which they are members (to contribute to a good society). The examples proposed above of voluntary simplifiers, loving parents, mindful homemakers, eco-conscious homeowners, or fashion-loving teen- 
agers illustrate our claim that consumption decisions are frequently experienced as activities that are necessary for the achievement of the goods internal to practices with which individuals try to craft a coherent life narrative within the traditions of their communities. In this context, virtues are those positive character traits that help consumers discern and enact the decisions that lead to the achievement of those goods.

\section{CONCLUSION}

Is it possible to develop virtues in consumption? In this paper, we have furthered the conversation on consumer ethics by arguing the relevance of virtue ethics approach. We contend that consumers may develop some specific virtues related to the acquisition, use and disposal of objects and services. As a domain-relative practice, moderate and wise consumption provides access to the internal goods of practices and preserves them from the persistent threat of an excessive concern with external goods. Consumption can also become an occasion and provide symbolic resources for the crafting of one's life narrative as well as for the improvement of the community's moral fabric. Virtue ethics understands that sustainable or caring practices are worthy and must be carried out not for their own sake but also as a means for us and others to develop virtues and flourish as human beings.

Virtue ethics holds at least three advantages over other ethical approaches for the analysis of consumption. First, both deontology and consequentialism help us think through the ethical dimensions of consumption, but they do not explore the developmental dynamics that emerge as a consequence of agents' engagement in consumption practices. Similar to deontology, our conception of virtue ethics recognizes that sound principles help discern right from wrong and that some of those principles must never be broken. Along with consequentialism, virtue ethics considers consequences as criteria for moral evaluation. However, virtue ethics stands out in recognizing and integrating as its central element the identity work that consumer culture theory has brought into relief so vividly. Consumers change for the better or for the worse - that is, they acquire virtues or vices, respectively - as a result of their consumption decisions, and this change in turn makes consumers more or less apt to pass sound moral judgments. This moral development constitutes a thread in the agent's overall quest for discerning what 'a morally good life' means for her.

A second advantage of virtue ethics' emphasis on the consumer's developmental dynamics is its integration of everyday consumption into ethical consumption. A few creative minorities face our pervasive consumer culture by defending specific consumption patterns. While their efforts are undoubtedly praiseworthy, we contend that ethical consumption is not limited to the purchase of a subset of goods or services defined as 'ethical' or to the participation in social or political causes such as anti-pollution boycotts, fair trade networks or slow movements but extends to all types of practices as long as they are integrated into the individual's search for a morally good life and contribute to the good of the community in which she lives. Obviously, it will remain at the consumers' discretion-with the much needed help of business companies, marketing departments, and the media and advertising 
industry - to realize this possibility and to articulate a narrative order in which consumption practices become a context and occasion for the development of virtues.

A third advantage of our approach is a practical one. Virtue ethics is an apt approach to induce people to consume moderately, thereby fostering human and environmental flourishing. Abundant research in social psychology stemming from Steele's (1988) seminal piece on identity-based behavior shows that behavioral change is stronger and longer-lasting when couched in coherent terms with salient traits of the agent. Virtue ethics, with its emphasis on the development of the consumer's identity, is in a better position than other theories to take advantage of this motivational power to change a person's behavior and character toward more ethical consumption across all types of social groups.

\section{NOTES}

The authors thank Marta M. Elvira, Joan Fontrodona, Domènec Melé, Alejo J. Sison, and three anonymous $B E Q$ reviewers for helpful comments on previous drafts of the article. We also thank associate editor Kenneth Goodpaster for his scrupulous work and thoughtful comments.

1. We thank one anonymous reviewer for these insights.

\section{REFERENCES}

Adams, M., \& Raisborough, J. 2010. Making a difference: Ethical consumption and the everyday. The British Journal of Sociology, 61(2): 256-74.

http://dx.doi.org/10.1111/j.1468-4446.2010.01312.x

Ahuvia, A. C. 2005. Beyond the extended self: Loved objects and consumers' identity narratives. Journal of Consumer Research, 32(1): 171-84. http://dx.doi.org/10.1086/429607

Albers-Miller, N. D. 1999. Consumer misbehavior: Why people buy illicit goods. Journal of Consumer Marketing, 16(3): 273-87. http://dx.doi.org/10.1108/07363769910271504

Alexander, S., \& Ussher, S. 2012. The voluntary simplicity movement: A multi-national survey analysis in theoretical context. Journal of Consumer Culture, 12(1): 66-86. http://dx.doi.org/10.1177/1469540512444019

Anscombe, G. E. 1958. Modern moral philosophy. Philosophy, 33(124): 1-19. http://dx.doi.org/10.1017/S0031819100037943

Aranzadi, J. 2011. The possibilities of the acting person within an institutional framework: Goods, norms, and virtues. Journal of Business Ethics, 99(1): 87-100. http://dx.doi.org/10.1007/s10551-011-0751-y

Aristotle. 2001. Nicomachean Ethics. In R. McKeon (Ed.), The basic works of Aristotle: 935-1125. New York: Randon House.

Arnould, E. J. 2006. Consumer culture theory: Retrospect and prospect. European Advances in Consumer Research, 7(1): 605-07.

Arnould, E. J., \& Thompson, C. J. 2005. Consumer culture theory (CCT): Twenty years of research. Journal of Consumer Research, 31(4): 868-82.

http://dx.doi.org/10.1086/426626 
Audi, R. 2012. Virtue ethics as a resource in business. Business Ethics Quarterly, 22(2): 273-91. http://dx.doi.org/10.5840/beq201222220

Barber, B. R. 2008. Consumed: How markets corrupt children, infantilize adults, and swallow citizens whole. New York: W. W. Norton and Company.

Barnett, C., Cafaro, P., \& Newholm, T. 2005. Philosophy and ethical consumption. In R. Harrison, T. Newholm, \& D. Shaw (Eds.), The ethical consumer: 11-24. London: Sage.

Barnett, C., Cloke, P., Clark, N., \& Malpass, A. 2005. Consuming ethics: Articulating the subjects and spaces of ethical consumption. Antipode, 37(1): 23-45. http://dx.doi.org/10.1111/j.0066-4812.2005.00472.x

Barrientos, S., \& Smith, S. 2007. Do workers benefit from ethical trade? Assessing codes of labour practice in global production systems. Third World Quarterly, 28(4): 713-29. http://dx.doi.org/10.1080/01436590701336580

Beabout, G. R. 2012. Management as a domain-relative practice that requires and develops practical wisdom. Business Ethics Quarterly, 22(2): 405-32. http://dx.doi.org/10.5840/beq201222214

Beadle, R. 2013. Managerial work in a practice-embodying institution: The role of calling, the virtue of constancy. Journal of Business Ethics, 113(4): 679-90. http://dx.doi.org/10.1007/s10551-013-1678-2

Beadle, R., \& Moore, G. 2006. MacIntyre on virtue and organization. Organization Studies, 27(3): 323-40. http://dx.doi.org/10.1177/0170840606062425

2011. MacIntyre, neo-Aristotelianism and organization theory. Research in the Sociology of Organisations, 32: 85-121. http://dx.doi.org/10.1108/S0733-558X(2011)0000032006

Belk, R. W. 1988. Possessions and the extended self. Journal of Consumer Research, 15 (September): 139-68. http://dx.doi.org/10.1086/209154

Belk, R. W., \& Pollay, R. W. 1985. Images of ourselves: The good life in twentieth century advertising. Journal of Consumer Research, 11 (March): 887-97. http://dx.doi.org/10.1086/209024

Black, I. R., \& Cherrier, H. 2010. Anti-consumption as part of living a sustainable lifestyle: Daily practices, contextual motivations and subjective values. Journal of Consumer Behavior, 9(6): 437-53. http://dx.doi.org/10.1002/cb.337

Bright, D. S., Winn, B. A., \& Kanov, J. 2014. Reconsidering virtue: Differences of perspective in virtue ethics and the positive social sciences. Journal of Business Ethics, 119(4): 445-60. http://dx.doi.org/10.1007/s10551-013-1832-x

Brinkmann, J., \& Peattie, K. 2008. Consumer ethics research: Reframing the debate about consumption for good. EJBO Electronic Journal of Business Ethics and Organizational Studies, 13(1): 22-31.

Caruana, R. 2007. Morality and consumption: Towards a multidisciplinary perspective. Journal of Marketing Management, 23(3-4): 207-25. http://dx.doi.org/10.1362/026725707X196341

Caruana, R., \& Chatzidakis, A. 2013. Consumer social responsibility (cnsr): Toward a multi-level, multi-agent conceptualization of the "other csr." Journal of Business Ethics, 113(4): 1-16. 
Chatzidakis, A., Hibbert, S., Mittusis, D., \& Smith, A. 2004. Virtue in consumption? Journal of Marketing Management, 20(5-6): 526-43.

http://dx.doi.org/10.1362/0267257041323972

Cherrier, H., \& Murray, J. B. 2007. Reflexive dispossession and the self: Constructing a processual theory of identity. Consumption, Markets \& Culture, 10(1): 1-29. http://dx.doi.org/10.1080/10253860601116452

Cho, S., \& Krasser, A. H. 2011. What makes us care? The impact of cultural values, individual factors, and attention to media content on motivation for ethical consumerism. International Social Science Review, 86(1-2): 3-23.

Cohen, M. J., \& Murphy, J. 2001. Exploring sustainable consumption: Environmental policy and the social sciences. Oxford: Elsevier.

Craig-Lees, M., \&, Hill, C. 2002. Understanding voluntary simplifiers. Psychology and Marketing, 1(2): 187-210. http://dx.doi.org/10.1002/mar.10009

Douglas, M., \& Isherwood, B. C. 1979. The world of goods: Towards an anthropology of consumption. London: Basic Books.

Elgin, D. 2010. Voluntary simplicity: Toward a way of life that is outwardly simple, inwardly rich. New York: Harper.

Etzioni, A. 1998. Voluntary simplicity characterization, select psychological implications, and societal consequences. Journal of Economic Psychology, 19: 619-43.

Ferrero, I. \& Sison, A. G. Forthcoming. A quantitative analysis of authors, schools and themes in virtue ethics articles in business ethics and management journals (19802011). Business Ethics: A European Review.

Fournier, S. J. 2000. Building brand community on the Harley-Davidson posse ride. Case ref. 9-501-015. Harvard Business School Publishing.

Friedman, J. 1994. Consumption and identity. London: Routledge.

Fukukawa, K. 2003. A theoretical review of business and consumer ethics research: Normative and descriptive approaches. The Marketing Review, 3: 381-401. http://dx.doi.org/10.1362/146934703771910035

Fullerton, S., Kerch, K. B., \& Dodge, H. R. 1996. Consumer ethics: An assessment of individual behavior in the marketplace. Journal of Business Ethics, 15(7): 805-14. http://dx.doi.org/10.1007/BF00381744

Gambrel, J. C., \& Cafaro, P. 2010. The virtue of simplicity. Journal of Agricultural and Environmental Ethics, 23(1-2): 85-108. http://dx.doi.org/10.1007/s10806-009-9187-0

Grigsby, M. 2004. Buying time and getting by: The voluntary simplicity movement. New York: State University of New York Press.

Harrison, R., Newholm, T., \& Shaw. D. (Eds.). 2005. The ethical consumer. London: Sage. Hochschild, A. 2012. The second shift: Working families and the revolution at home. New York: Penguin.

Humphery, K. 2010. Excess: Anti-consumerism in the west. London: Polity Press.

Hursthouse, R. 1999. On virtue ethics. Oxford: Oxford University Press.

Johnson, B. 2004. Review essay: Simply identity work? The voluntary simplicity movement. Qualitative Sociology, 27(4): 527-30. http://dx.doi.org/10.1023/B:QUAS.0000049267.29699.d9

Keat, R. 2000. Cultural goods and the limits of the market. London: Palgrave. http://dx.doi.org/10.1057/9780230595767 
2008. Practices, firms and varieties of capitalism. Philosophy of Management, 7(1): 77-91. http://dx.doi.org/10.5840/pom2008718

Koehn, D. 2000. What is practical judgment? Professional Ethics Journal, 8(3-4): 3-18. http://dx.doi.org/10.5840/profethics200083/420

Kopytoff, I. 1986. The cultural biography of things. In A. Appadurai (Ed.), The social life of things: 64-91. Cambridge: Cambridge University Press.

Kornberger, M. 2010. Brand society: How brands transform management and lifestyle. Cambridge: Cambridge University Press.

http://dx.doi.org/10.1017/CBO9780511802881

Kozinets, R. V., \& Handelman, J. 1998. Ensouling consumption: A netnographic exploration of the meaning of boycotting behavior. Advances in Consumer Research, 25(1): 475-80.

Lepper, M. R., Greene, D., \& Nisbett, R. E. 1973. Undermining children's intrinsic interest with extrinsic reward: A test of the "Overjustification" hypothesis. Journal of Personality and Social Psychology, 28: 129-37. http://dx.doi.org/10.1037/h0035519

Lorenzen, J. A. 2012. Going green: The process of lifestyle change. Sociological Forum, 27: 94-116. http://dx.doi.org/10.1111/j.1573-7861.2011.01303.x

Luedicke, M. K., Thompson, C. J., \& Giesler, M. 2010. Consumer identity work as moral protagonism: How myth and ideology animate a brand-mediated moral conflict. Journal of Consumer Research, 36 (April): 1016-32. http://dx.doi.org/10.1086/644761

MacIntyre, A. 1992. Plain persons and moral philosophy. American Catholic Philosophical Quarterly, 66(1): 3-19. http://dx.doi.org/10.5840/acpq199266144

. 1994. A partial response to my critics. In J. Horton \& S. Mendus (Eds.), After MacIntyre: Critical perspectives on the work of Alasdair MacIntyre: 283-304. Cambridge: Polity Press.

1999. Dependent rational animals: Why human beings need the virtues. Chicago: Open Court.

2007. After virtue: A study in moral theory. London: Duckworth.

MacIntyre, A., \& Dunne, J. 2002. Alasdair MacIntyre on education: In dialogue with Joseph Dunne. Journal of Philosophy of Education, 36(1): 1-19.

http://dx.doi.org/10.1111/1467-9752.00256

Marion, G., \& Nairn, A. 2011. "We make the shoes, you make the story." Teenage girls' experience of fashion: Bricolage, tactics and narrative identity. Consumption, Markets \& Culture, 14(1): 29-56. http://dx.doi.org/10.1080/10253866.2011.541181

Mayo, M. A., \& Marks, L. J. 1990. An empirical investigation of a general theory of marketing ethics. Journal of the Academy of Marketing Science, 18(2): 163-71. http://dx.doi.org/10.1007/BF02726432

McAlexander, J. H., Schouten, J. W., \& Koenig, H. F. 2002. Building brand community. The Journal of Marketing, 66 (January): 38-54. http://dx.doi.org/10.1509/jmkg.66.1.38.18451

Melé, D. 2009. Integrating personalism into virtue-based business ethics: The personalist and the common good principles. Journal of Business Ethics, 88(1): 227-44. http://dx.doi.org/10.1007/s10551-009-0108-y 
Micheletti, M., \& Stolle, D. 2008. Fashioning social justice through political consumerism, capitalism, and the internet. Cultural Studies, 22(5): 749-69.

http://dx.doi.org/10.1080/09502380802246009

Miller, D. 1998. A theory of shopping. Ithaca, NY: Cornell University Press.

2001. The dialectics of shopping. Chicago: The University of Chicago Press.

Moore, G. 2004. The Fair Trade movement: Parameters, issues and future research. Journal of Business Ethics, 53(1-2): 73-86.

http://dx.doi.org/10.1023/B:BUSI.0000039400.57827.c3

2005a. Corporate character: Modern virtue ethics and the virtuous corporation. Business Ethics Quarterly, 15(4): 659-85.

http://dx.doi.org/10.5840/beq200515446

2005b. Humanizing business: A modern virtue ethics approach. Business Ethis Quarterly, 15(2): 237-55. http://dx.doi.org/10.5840/beq200515212

Muncy, J. A., \& Vitell, S. J. 1992. Consumer ethics: An investigation of the ethical beliefs of the final consumer. Journal of Business Research, 24(4): 297-311.

http://dx.doi.org/10.1016/0148-2963(92)90036-B

Muniz, A. M., \& O'Guinn, T. C. 2001. Brand community. Journal of Consumer Research, 27 (March): 412-32. http://dx.doi.org/10.1086/319618

Murray, J. B. 2002. The politics of consumption: A re-inquiry on Thompson and Haytko's (1997) "Speaking of Fashion." Journal of Consumer Research, 29(3): 427-40. http://dx.doi.org/10.1086/344424

Pettit, P. 1991. Consequentialism. In P. Singer (Ed.), A companion to ethics: 230-40. Oxford: Wiley-Blackwell.

Ritzer, G. 2001. Explorations in the sociology of consumption: Fast food, credit cards and casinos. London: Sage.

Roberts, A. 1998. Three exceptional figures. The UNESCO Courier, January: 15-16.

Röcklinsberg, H., \& Sandin, P. 2013. The ethics of consumption: The citizen, the market, and the law. Wageningen: Academic Publishers. http://dx.doi.org/10.3920/978-90-8686-784-4

Sassatelli, R. 2007. Consumer culture. London: Sage.

Sayer, A. R. 2003. (De-)Commodification, consumer culture and moral economy. Environment and Planning D: Society and Space, 21(3): 341-57. http://dx.doi.org/10.1068/d353

Schlegelmilch, B. B., \& Öberseder, M. 2010. Half a century of marketing ethics: Shifting perspectives and emerging trends. Journal of Business Ethics, 93(1): 1-19. http://dx.doi.org/10.1007/s10551-009-0182-1

Schor, J. 1992. The overworked American. New York: Basic Books. 1999. The overspent American. New York: Harper.

Segal, J. M. 1999. Graceful simplicity: Toward a philosophy and politics of simple living. London: Living, H. Holt and Co.

Shaw, D., \& Newholm, T. 2002. Voluntary simplicity and the ethics of consumption. Psychology and Marketing, 19(2): 167-85. http://dx.doi.org/10.1002/mar.10008 
Shaw, D., \& Shiu, E. 2002. An assessment of ethical obligation and self-identity in ethical consumer decision-making: A structural equation modeling approach. International Journal of Consumer Studies, 26: 286-93. http://dx.doi.org/10.1046/j.1470-6431.2002.00255.x

Shaw, D., Shiu, E., \& Clarke, I. 2000. The contribution of ethical obligation and self-identity to the theory of planned behavior: An exploration of ethical consumers. Journal of Marketing Management, 16(8): 879-94. http://dx.doi.org/10.1362/026725700784683672

Sison, A. G., \& Fontrodona, J. 2012. The common good of the firm in the AristotelianThomistic tradition. Business Ethics Quarterly, 22(2): 211-46. http://dx.doi.org/10.5840/beq201222218

Sklair, L. 2002. Globalization: Capitalism and its alternatives. Oxford: Oxford University Press.

Steele, C. M. 1988. The psychology of self-affirmation: Sustaining the integrity of the self. In L. Berkowitz (Ed.), Advances in experimental social psychology, vol. 21: 261-302. New York: Academic Press.

Swaidan, Z. 2012. Culture and consumer ethics. Journal of Business Ethics, 108(2): 1-13. http://dx.doi.org/10.1007/s10551-011-1070-z

Swanton, C. 2003. Virtue ethics: A pluralistic view. Oxford: Oxford University Press. http://dx.doi.org/10.1093/0199253889.001.0001

Thompson, C. J. 1996. Caring consumers: Gendered consumption meanings and the juggling lifestyle. Journal of Consumer Research, 22 (March): 388-407. http://dx.doi.org/10.1086/209457

Thompson, C. J., \& Haytko, D. L. 1997. Speaking of fashion: Consumers' uses of fashion discourses and the appropriation of countervailing cultural meanings. Journal of Consumer Research, 24(1): 15-42. http://dx.doi.org/10.1086/209491

Tseëlon, E. 2011. Introduction: A critique of the ethical fashion paradigm. Critical Studies in Fashion \& Beauty, 2: 3-68. http://dx.doi.org/10.1386/csfb.2.1-2.3_2

Vitell, S. J. 2003. Consumer ethics research: Reviews, synthesis and suggestions for the future. Journal of Business Ethics, 43(1-2): 33-47. http://dx.doi.org/10.1023/A:1022907014295

Vitell, S. J., \& Hunt, S. D. 1990. The general theory of marketing ethics: A partial test of the model. Research in Marketing, 10: 237-65.

Vitell, S. J., \& Muncy, J., 1992. Consumer ethics: An empirical investigation of factors influencing ethical judgments of the final consumer. Journal of Business Ethics, 11(8): 585-97. http://dx.doi.org/10.1007/BF00872270

Vitell, S. J., Singhapakdi, A., \& Thomas, J. 2001. Consumer ethics: An application and empirical testing of the Hunt-Vitell theory of ethics. Journal of Consumer Marketing, 18(2): 153-78. http://dx.doi.org/10.1108/07363760110386018

von Krogh, G., Haefliger, S., Spaeth, S., \& Wallin, M. W. 2012. Carrots and rainbows: Motivation and social practice in open software source development. MIS Quarterly, 36(2): 649-76.

Warde, A. 2005. Consumption and theories of practice. Journal of Consumer Culture, 5(2): 131-53. http://dx.doi.org/10.1177/1469540505053090 